\title{
Contents of The American Journal of Psychiatry
}

February 1996

Volume 153

Editorial

Imaging for the clinical psychiatrist: facts, fantasies, and other musings. Jonathan D. Brodie

Images in Neuroscience

Neuroimaging, V: PET and the $\left[{ }^{15} \mathrm{O}_{\mathrm{H}} \mathrm{O}\right.$ technique, part 3: finding the location of significant regions.

Essay by N.C.A.

Special Articles

Initiation and adaptation: a paradigm for understanding psychotropic drug action. Steven E. Hyman and

Eric J. Nestler

Women with bipolar illness: clinical and research issues. Ellen Leibenluft

Regular Articles

Demonstration in vivo of reduced serotonin responsivity in the brain of untreated depressed patients. J. John Mann, Kevin M. Malone, David J. Diehl, James Perel, Thomas B. Cooper and Mark A. Mintun

[ ${ }^{123}$ I] IBZM SPECT for imaging of striatal $\mathrm{D}_{2}$ dopamine receptors in 56 schizophrenic patients taking various neuroleptics. Edzard Klemm, Frank Grünwald, Siegfried Kasper, Christian Menzel, Karl Broich, Peter Danos, Karl Reichmann, Christian Krappel, Olaf Rieker, Bernd Briele, Andreas L. Hotze, Hans-Jürgen Möller and Hans-Jürgen Biersack

PET and MRI of the thalamus in never-medicated patients with schizophrenia. Monte S. Buchsbaum Toshiyuki Someya, Chuck Ying Teng, Lennart Abel, Samuel Chin, Ahmad Najafi, Richard J. Haier, Joseph Wu and William E. Bunney, Jr

Functional magnetic resonance imaging of schizophrenic patients and comparison subjects during word production. Deborah A. Yurgelun-Todd, Christine M. Waternaux, Bruce M. Cohen, Staci A. Gruber, Camper D. English and Perry F. Renshaw

Cerebral blood flow changes in limbic regions induced by unsolvable anagram tasks. Frank Schneider, Raquel E. Gur, Abass Alavi, Martin E. P. Seligman, Lyn Harper Mozley, Robin J. Smith, P. David Mozley and Ruben C. Gur

Functioning and well-being of patients with panic disorder. Cathy Donald Sherbourne, Kenneth B. Wells and Lewis L. Judd

Predictors of PTSD in injured trauma survivors: a prospective study. Arieh $Y$. Shalev, Tuvia Peri, Laura Canetti and Shaul Schreiber

Controlled prospective study on the mental health of women following pregnancy loss. Hettie J. E. M. Janssen, Marian C. J. Cuisinier, Kees A. L. Hoogduin and Kees P. H. M. de Graauw

A double-blind trial of haloperidol, chlorpromazine, and lorazepam in the treatment of delirium in hospitalized AIDS patients. William Breitbart, Rocco Marotta, Meredith M. Platt, Henry Weisman, Maria Derevenco, Carmen Grau, Kathy Corbera. Susan Raymond, Stephen Lund and Paul Jacobsen

Interest in physician-assisted suicide among ambulatory HIV-infected patients. William Breitbart, Barry D. Rosenfeld and Steven D. Passik

Relationship of aggressive behavior to other neuropsychiatric symptoms in patients with Alzheimer's disease. Dag Aarsland, Jeffrey L. Cummings, Gersev Yenner and Bruce Miller

Demographics, family history, premorbid functioning, developmental characteristics, and course of patients with deteriorated affective disorder. Carina Vocisano, Daniel N. Klein, Richard S. E. Keefe, Evelyn R. Dienst and Margaret M. Kincaid

Managed care constraints on psychiatrists' hospital practices: bargaining power and professional autonomy.

Mark Schlesinger, Robert A. Dorwart and Sherrie S. Epstein

Clinical Case Conference

Acute manic episodes in pregnancy. Molly Finnerty, Ze'ev Levin and Laura J. Miller

Images in Psychiatry

The Maudsley. Essay by Robin M. Murray

Brief Reports

Qualitative changes in hallucinations. Laura J. Miller

No evidence for allelic association between schizophrenia and a polymorphism determining high or low catechol O-methyltransferase activity. J. K. Daniels, N. M. Williams, J. Williams, L. A. Jones, A. G. Cardno, K. C. Murphy, G. Spurlock, B. Riley, P. Scambler, P. Asherson, P. McGuffin and M. J. Owen

Further tests for linkage of bipolar affective disorder to the tyrosine hydroxylase gene locus on chromosome 11 p15 in a new series of multiplex British affective disorder pedigrees. Ciaran Smyth, Gursharan Kalsi, Jon Brynjolfsson, Jane O'Neill, David Curtis, Larry Rifkin, Eamon Moloney, Patrice Murphy, Robin Sherrington, Hannes Petursson and Hugh Gurling

Childhood physical and sexual abuse in patients with anxiety disorders and in a community sample.

Murray B. Stein, John R. Walker, Geri Anderson, Andrea L. Hazen, Colin A. Ross, Gloria Eldridge and David R. Forde

Social phobia in adults with stuttering. Murray B. Stein, Allison Baird and John R. Walker

Experience of a "slip" among alcoholics treated with naltrexone or placebo. Stephanie S. O'Malley, Adam J.

Jaffe, Sarah Rode and Bruce J. Rounsaville 


\section{New Brief Pulse ECT with Computer-Assisted Easy Seizure Monitoring}
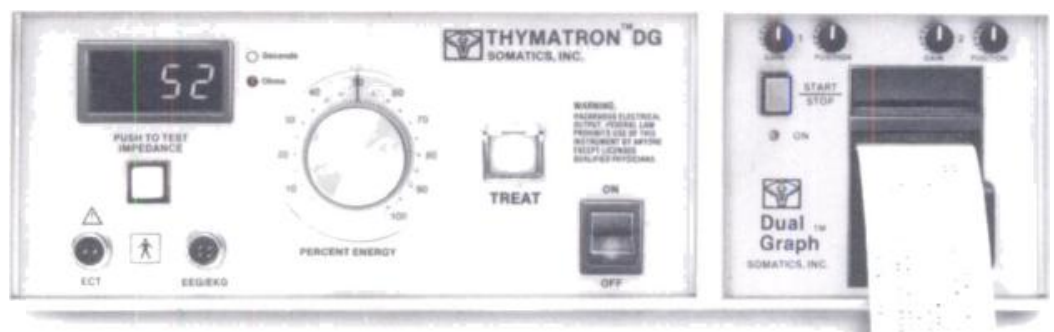

\section{Somatics Thymatron ${ }^{\text {TM }}$ DGx}

- Automatically monitors your choice of EEG-EEG, EEG-ECG, or EEG-EMG and determines EEG and motor seizure lengths.

- Computer-measured seizure quality, including postictal EEG suppression, seizure energy index.

- Up to 8 seconds stimulus duration; pulsewidth as short as $0.5 \mathrm{~ms}$.

- Single dial sets stimulus charge by age; high-dose option available.

- FlexDial ${ }^{\mathrm{TM}}$ adjusts pulsewidth and frequency without altering dose.

Distributed in the U.K. by:

DANTEC Electronics, Ltd.

Garonor Way

Royal Portbury

Bristol BS20 9XE

TEL (44) 1275-375333

FAX (44) 1275-375336

Distributed in India by:

DIAGNO.SYS

New Delhi

TEL (91) 11-644-0546

FAX (91) 11-622-9229
Distributed in Australia by:

MEECO Holdings Pty. Ltd. 10 Seville St.

North Parramatta NSW 2151

Australia

TEL (61) 2630-7755

FAX (61) 2630-7365

Distributed in Pakistan by:

IQBAL \& CO.

Islamabad

TEL (92) 51-291078

FAX (92) 51-281623
Distributed in New Zealand by: WATSON VICTOR, Ltd. 4 Adelaide Rd.

Wellington, New Zealand

TEL (64) 4-385-7699

FAX (64) 4-384-4651

Distributed in South Africa by: DELTA SURGICAL

Craighall

TEL (27) 11-792-6120

FAX (27) 11-792-6926

Distributed in U.S.A. and Canada by:

SOMATICS, INC., 910 Sherwood Drive \# 17, Lake Bluff, IL, 60044, U.S.A. Fax: (847) 234-6763; Tel: (847) 234-6761 


\section{Leadership isn't given.}

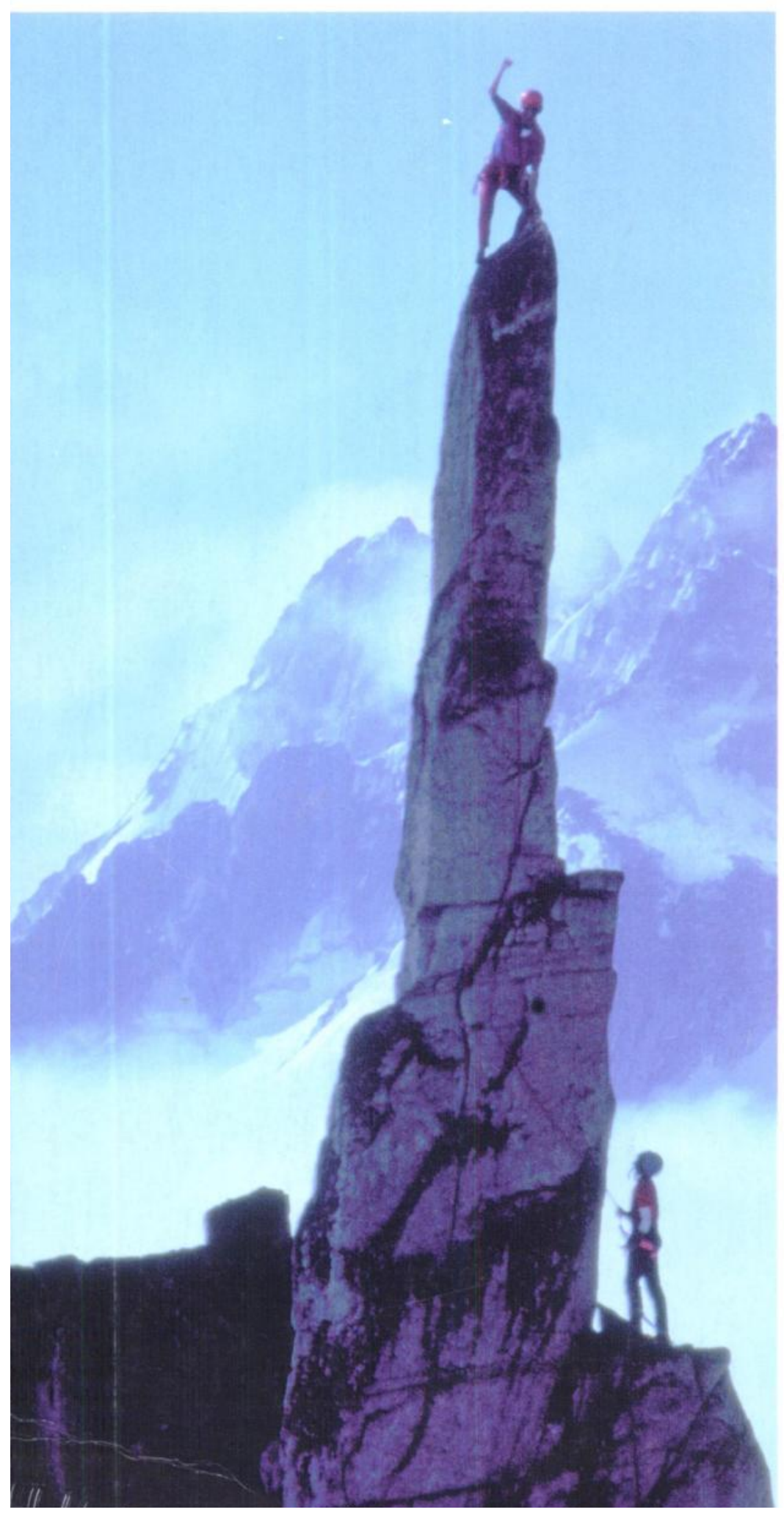

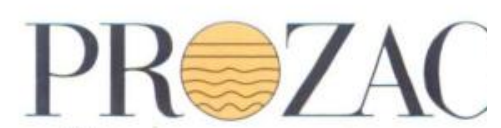
fluoxetine The World's No. 1 prescribed antidepressant branc Funber information is availatile on request from:
Dista Products Limited. Dextra Coum. Chapel Hill Basingstoke. Hamphire R621 5s

Legal Category: POM.

'PROZAC' is a Dista trade mark. EDPIBTA Date of preparation: August $1995 \quad$ PZ68 